\title{
O amor é pop: canções e posicionamento pop-rock para crianças
}

\section{Love is pop: songs and pop-rock positioning for children}

\section{El amor es pop: canciones y posicionamiento pop-rock para niños}

(iD) Maria das Dores Nogueira Mendes

Universidade Federal do Ceará (UFC), Fortaleza, Ceará, Brasil. E-mail: dasdoresnm@yahoo.com.br.

iD 9

José Wesley Vieira Matos

Universidade Federal do Ceará (UFC), Fortaleza, Ceará, Brasil. E-mail: jose.wesley98@alu.ufc.br.

Resumo: Este estudo investiga a construção e representação dos relacionamentos afetivos, com realce para o aspecto amoroso, no posicionamento Pop-rock para crianças, tendo como corpus as produções do grupo Pato Fu (2010, 2017), do heterônimo Adriana Partimpim (2004, 2009, 2012), e do grupo Pequeno Cidadão (2009, 2012, 2016). Para isso, tomamos como referencial os teóricos discutidos no projeto INVOCANÇÕES, ligado ao Grupo Discuta (UFC), tais como Maingueneau (2001a, 2001b, 2005, 2006, 2015), Costa (2012, 2013), Mendes (2013), Gonzalez (2014), Mendes (2017), entre outros. Assim, investigamos qual o tratamento dado a esse aspecto por meio da análise do ethos discursivo dos distintos enunciadores, da construção cenográfica e do investimento vocal do locutor. Dessa maneira, pensamos como essas características contribuem para o delineamento do posicionamento em que se inscrevem no campo literomusical. A análise aponta que o amor constitui, para além de uma temática rica e recorrente no posicionamento, uma bandeira que compõe o núcleo identitário "revolucionário" do Pop-rock para crianças.

Palavras-chave: Discurso literomusical. Relacionamento amoroso. Posicionamento pop-rock para crianças. Retextualização. 
Abstract: This study investigates the construction and representation of affective relationships, highlighting the love aspect, in the Pop-rock positioning for children, having as corpus the productions of the group Pato Fu (2010, 2017), of the heterym Adriana Partimpim (2004, 2009, 2012) and the Pequeno Cidadão Group (2009, 2012, 2016). To this end, we take as reference the theorists discussed in the project INVOCANÇÕES, linked to the group Discuta (UFC), such as Maingueneau (2001a, 2001b, 2005, 2006, 2015), Costa (2012, 2013), Mendes (2013), Gonzalez (2014), Mendes (2017), among others. Thus, we investigate the treatment given to this aspect through the analysis of the discursive ethos of the distinguished enunciators, the cenographic construction and the voice investment of the announcer; Thus, we think how these characteristics contribute to the design of the positioning in which they are inscriptional in the literomusical field. The analysis points out that love constitutes, in addition to a rich and recurrent theme in positioning, a flag that makes up the "revolutionary" identity nucleus of Pop-rock for children.

Keywords: Literomusical discourse. Loving relationship. Pop-rock positioning for children. Retextualization.

Resumem: Este estudio investiga la construcción y representación de las relaciones afectivas, destacando el aspecto amoroso, en el posicionamiento Pop-rock para niños, teniendo como corpus las producciones del grupo Pato Fu (2010, 2017), del heterónimo Adriana Partimpim (2004, 2009, 2012) y el Grupo Pequeno Cidadão (2009, 2012, 2016). Para ello, tomamos como referencia a los teóricos discutidos en el proyecto INVOCANÇÕES, vinculados al grupo Discuta (UFC), como Maingueneau (2001a, 2001b, 2005, 2006, 2015), Costa (2012, 2013), Mendes (2013), Gonzalez (2014), Mendes (2017), entre otros. Así, investigamos el tratamiento dado a este aspecto a través del análisis del ethos discursivo de los distintos enunciadores, la construcción cenográfica y la inversión por voz del locutor. De esta forma, pensamos en cómo estas características contribuyen al diseño del posicionamiento en el que están inscriptos en el campo literomusical. El análisis señala que el amor constituye, además de un tema rico y recurrente en el posicionamiento, 
una bandera que compone el núcleo de identidad "revolucionaria" de Pop-rock para niños.

Palabras clave: Discursoliteromusical. Relación amorosa. Posicionamiento Pop-rock para niños. Retextualización.

Submetido em 27 de outubro de 2019.

Aceito em 22 de julho de 2020.

Publicado em 28 de outubro de 2020. 


\section{0 projeto INVOCANÇÕES}

Esta pesquisa se insere na terceira etapa do projeto de pesquisa Investimento vocal em canções para crianças (INVOCANÇÕES), ligado ao Grupo Discurso, cotidiano e práticas culturais - Grupo Discuta (UFC), que tem por objetivo finalizar e divulgar as pesquisas em torno dos posicionamentos do campo literomusical brasileiro para crianças. O projeto visa a caracterizar aspectos, principalmente vocais, que podem ser delineadores dos posicionamentos apresentados por Gonzalez (2014) - MPB para crianças, Canção de massa para crianças e Gospel para crianças - e o posicionamento delimitado pelo projeto INVOCANÇÕES em sua primeira fase Pop-rock para crianças.

Dessa forma, pretendemos contribuir para a caracterização do posicionamento destacado em nosso projeto, investigando a construção e representação dos relacionamentos afetivos, com ênfase para o aspecto amoroso. Em conformidade com o corpus geral do projeto, delimitamos a coleta de canções para essa análise nas produções dos(as) seguintes artistas/bandas: Adriana Partimpim (2004, 2009, 2012), heterônimo de Adriana Calcanhotto; grupo Pato Fu (2010, 2017), com o premiado projeto “Música de brinquedo", e grupo Pequeno Cidadão (2009, 2012, 2016), composto por artistas diversos, dedicado especialmente ao público infantil.

Os álbuns "Adriana Partimpim", segundo a intérprete Adriana Calcanhotto, surgiram da ideia de pensar que as músicas para crianças "seria[m] um gênero musical mais solto, menos visado, menos patrulhado por regras e absolutos como são o rock, o pop..." (PARTIMPIM, s/d). Assim, ela considera esse tipo musical como um "não gênero". A cantora explica que esse heterônimo surgiu na sua infância, era assim que ela se apresentava às pessoas. Além disso, declara que o álbum não é estritamente para crianças e afirma: "jamais pensei em excluir os adultos. A intenção sempre foi trazer as crianças, formar um novo público" (CALCANHOTTO, 2004). 
"Música de brinquedo" são os dois álbuns de Pato Fu. A ideia, segundo a principal vocalista, Fernanda Takai, surgiu após a audição do CD "Snoopy's Beatles: Classiks on Toys"1 e foi levada mais a sério após o nascimento de sua filha Nina. Em diversas entrevistas, a cantora afirma que o álbum não foi, inicialmente, pensado para crianças: "É um disco de repertório pop, adulto, filtrado por instrumentos de brinquedo ou miniaturas" (TAKAI, 2011). Contudo, desde o primeiro fonograma, as produções ganharam espaço em meio à esfera infantil. Uma boa prova disso foi o primeiro álbum, em 2011, ter sido premiado no Grammy Latino como melhor disco infantil.

Já o projeto "Pequeno Cidadão", diferente dos anteriores, enfatiza que seu público-alvo são as crianças e assim se define no site oficial do grupo: "Somos um grupo de rock divertido e educativo para crianças bagunceiras e muito sabidas." (PEQUENO CIDADÃO, 2019). O grupo é formado pelos fundadores Edgard Scandurra, Taciana Barros e Antônio Pinto, pelos filhos destes e, também, por vários artistas convidados, como Arnaldo Antunes e Ziraldo. Todos esses mencionados tornam ainda mais evidente a eleição do pop-rock como gênero para crianças, considerando a filiação deles com bandas de rock dos anos 1980 e 1990.

\subsection{O amor nos posicionamentos para crianças}

Além das produções que embasam nosso projeto, os norteamentos sobre o campo literomusical brasileiro para adultos e para crianças de Costa $(2012,2013)$, os posicionamentos para crianças delineados por Gonzalez (2014) e as considerações dos investimentos vocais de Mendes (2013), esta pesquisa dá-se como uma continuação do trabalho "Relacionamento amoroso em canções para crianças" (MATOS, 2020), aprofundando os resultados obtidos no posicionamento pop-rock para crianças.

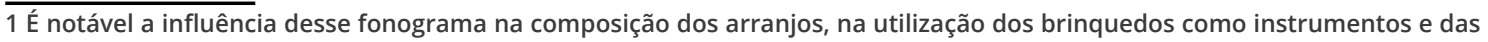
vozes infantis nas produções para crianças de Pato Fu. 
O amor é pop: canções e posicionamento pop-rock para crianças

Maria das Dores Nogueira Mendes • José Wesley Vieira Matos

Segundo Costa (2012), as produções intersemióticas musicais populares brasileiras constituem um campo discursivo ${ }^{2}$ de relações complexas. Assim, é possível notar as interações entre os diversos posicionamentos ${ }^{3}$ que se inscrevem nesse campo e o modo de enunciar distinto de cada um desses. Dessa forma, Gonzalez (2014) percebe e delineia os principais aspectos discursivos nos quais os posicionamentos de produções literomusicais para crianças investem. Partimos, portanto, desse percurso teórico localizado na Análise do Discurso de linha francesa para investigar e aprofundar as caracterizações desse recorte de produções voltadas para crianças.

Neste primeiro trabalho, recortamos uma canção, com a temática amorosa, representativa de cada posicionamento para crianças e obtivemos um quadro geral a respeito dos investimentos que cada um desses constrói. Analisamos as canções a partir de três conceitos teóricos: investimento ético, investimento cenográfico e investimento vocal; relacionando-os também com a concepção de criança e a construção da identidade de cada posicionamento. $O$ investimento do ethos discursivo segue a conceituação de Maingueneau $(2001 \mathrm{a}, 2001 \mathrm{~b}, 2006,2015)$ relacionada à imagem de si do enunciador criada na enunciação. $O$ investimento da cenografia, em conformidade com a definição de Maingueneau (2001a, 2001b, 2006, 2015), refere-se à encenação particular de cada texto construída na enunciação. Já o investimento vocal, conforme Mendes (2013), trata-se da consideração dos aspectos vocais como elementos discursivos fixados no fonograma de uma canção.

Manteremos, no presente estudo, os mesmos critérios para análise das canções em seus dois planos, o da letra e o da voz; com atenção ainda maior a como os resultados encontrados relacionam-se com a construção da identidade do posicionamento pop-rock para crianças, complexificando o que havíamos traçado em linhas gerais. Em síntese, esse posicionamento busca "instruir sobre o aspecto do relacionamento amoroso a partir da confor-

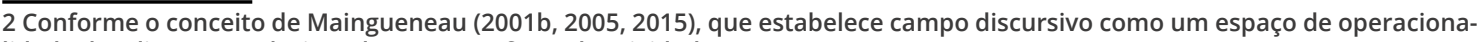
lidade dos discursos relacionado com as esferas de atividade.

3 Com base nas conceituações de Maingueneau (2001b, 2015), que se referem aos espaços internos do campo em que disputam diversas identidades em constante concorrência. 
O amor é pop: canções e posicionamento pop-rock para crianças

Maria das Dores Nogueira Mendes • José Wesley Vieira Matos

mação com a negação do par ideal junto com a afirmação da esperança em outro amor" (MATOS, 2020).

\section{Crise amorosa: "Um dilema que nem o cinema sabe resolver"}

No estudo anterior, havíamos elegido a canção "O Sol e a Lua" (2009), do grupo Pequeno Cidadão, como representativa do posicionamento pop-rock para crianças. Decerto, a canção apresenta uma das características mais marcantes e distinguidoras das demais produções de outros posicionamentos, a crise amorosa. Nessa canção, o Sol protagoniza uma idealização amorosa pela Lua, porém esta "o despreza e o deixa esperar" e responde o pedido de casamento com "Não sei, não sei, não sei/ Me dá um tempo". Assim, um narrador, prototipia da cenografia de narrativa, marcada também com trechos de voz falada, apresenta a diferença entre uma idealização e um relacionamento amoroso. O personagem Sol, apesar de estar apaixonado, possui um ethos projetado ${ }^{4}$ consciente da liberdade do outro. No fim da canção, outro enunciador, com identidade vocal de criança, consola o personagem Sol falando sobre a esperança em novas perspectivas: "Um dia você vai encontrar alguém/ Que com certeza vai te amar também".

A canção não é caso único no corpus, ao contrário, parece ser uma característica constitutiva da identidade pop-rock para crianças. Uma das marcas que mais sobressai é a presença de interrogações e dúvidas expressando o conflito entre se idealizar o amor e a impossibilidade de concretizá-lo em razão da recusa do outro, como ocorre na canção "Mesmo sem a gente" (PEQUENO CIDADÃO, 2016): “Tá tudo confuso, te perco ou te ganho?/ Minha cabeça gira em parafuso [...]" e na canção regravada, original de Ritchie, “Pelo interfone” (PATO FU, 2010), “Eu já não sei se eu vou, se eu fico

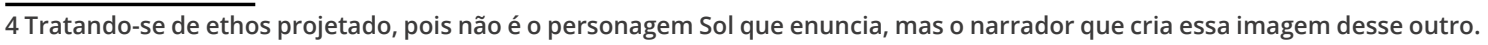


[...] Não quero te prender/ Mas não posso te perder/ Esse é um dilema que nem o cinema sabe resolver!".

Esse ethos conflituoso consigo e com o outro em relação às atitudes que se deve tomar diante de uma frustração amorosa perpassa outras canções como "Não se vá" (PATO FU, 2017), em que o enunciador suplica por uma nova chance esperançosa, e "Gatinha manhosa" (ADRIANA PARTIMPIM, 2007), em que o enunciador tenta solucionar um impasse comunicativo afetivo, reafirmando que o posicionamento não oculta um lado, geralmente, negativizado dos relacionamentos, mas explicita-o constantemente.

Gostaríamos ainda de mencionar o livro A fantástica viagem do Pequeno Cidadão (2010), mais especificamente o terceiro capítulo, intitulado "Crise amorosa". Neste capítulo, o protagonista Pec conhece a história (através da canção) de "O Sol e a Lua" (2009), narrada por seu companheiro de viagem, o pássaro uirapuru Tangará. Além do que já mencionamos sobre a canção, é interessante notar que, no livro, Pec pergunta o que acontecerá com o Sol após a desilusão amorosa e Tangará responde, com naturalidade, que há muitos caminhos, desde encontrar um novo amor até a possibilidade de passar a vida sozinho, causados pela escolha da Lua. Não nos dedicamos, ainda, a uma análise detalhada dessas produções literárias que se relacionam com os posicionamentos para crianças, contudo acreditamos que seja interessante analisar esse capítulo que explicita essa forte característica encontrada nas canções - que tratam de relacionamento amoroso - do pop-rock para crianças. 
O amor é pop: canções e posicionamento pop-rock para crianças

Maria das Dores Nogueira Mendes • José Wesley Vieira Matos

Figura 1. Ilustração de abertura do capítulo três do livro a fantástica viagem do pequeno cidadão

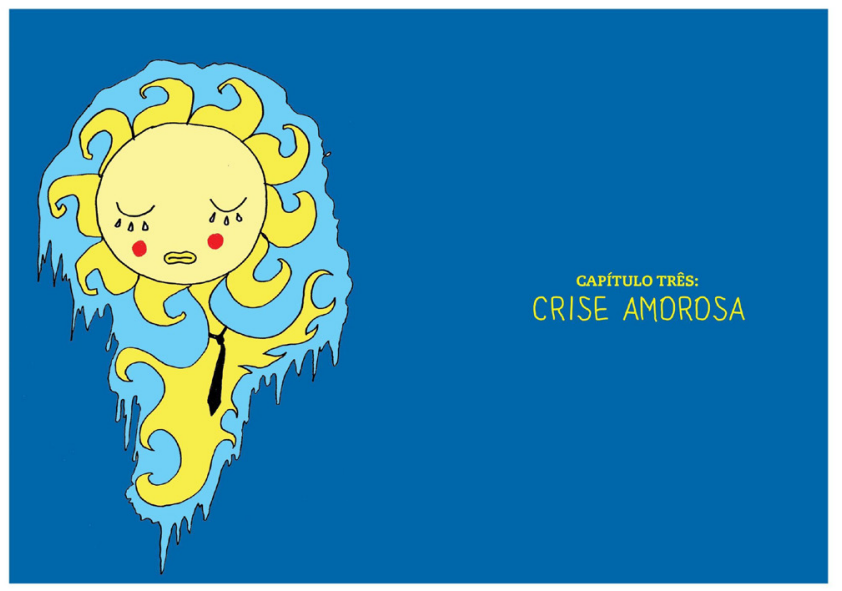

Fonte: Site oficial do grupo Pequeno Cidadão (2010)5.

\section{A solução: "Sim, sei que ainda vou crescer"}

Como mencionamos, no final da canção "O Sol e a Lua" investe-se em elementos conciliatórios para resolução do dilema posto. Percebemos que situação semelhante ocorre em "Mesmo sem a gente", em que o enunciador, que possui uma identidade vocal infantil, parece reconhecer uma atitude desagradável ou uma reação indesejada, reforçada pela cenografia confessional e de súplica, um pedido de desculpas, quando pede: "Me dê só mais um tempo e poderemos ser amigos simplesmente" (PEQUENO ClDADÃO, 2016). Conclui o enunciador com reflexões motivadoras e perspectivas de mudança: "Sim sei que ainda vou crescer/ Há muitas surpresas pelo caminho/ O sol se põe para depois nascer/ Tenho muito o que viver, muito o que aprender", complementando seu ethos conciliador com um aspecto esperançoso.

Em "Pelo interfone", o enunciador não está necessariamente diante de uma negação da idealização, mas encontra-se conturba-

5 Disponível em: https://www.pequenocidadaolojinha.com.br/produtos/a-fantastica-viagem-do-pequeno-cidadao-livro. Acesso em: abr. 2019. 
do pela falta de resposta concreta. Contudo, o ethos investido ao final é de esperança: "O dia vai chegar/ Uma noite a menos para a gente!" (PATO FU, 2010). Outro caso que à primeira vista pode parecer destoar dessa característica é a solução apresentada em "Gatinha manhosa", a de prender no coração. Parece que o enunciador escapa desse ethos que compreende a liberdade do outro e o infringe; contudo, a cenografia emotiva de manha e a recontextualização do termo "gatinha" permitem interpretar essa espécie de prisão como uma resposta afetiva positiva para o "conflito", que seria mais bem entendido como um jogo de charme, como sugere o trecho: "Briga só para depois/ ganhar mil carinhos de mim" (ADRIANA PARTIMPIM, 2007), uma paradoxal prisão carinhosa que não necessariamente se dá entre um casal, como aponta Mendes (2017).

Assim, notamos que há uma tendência de investimento em aspectos éticos conciliatórios esperançosos e em identidades vocais infantis para propor soluções aos conflitos dos amores não correspondidos ou incertos; o que podemos relacionar ao caráter pedagógico presente em todos os posicionamentos para crianças. Assim, os investimentos citados buscam criar uma identificação entre o enunciador infantil aconselhador e o delocutor ideal do discurso, a criança.

\section{Regravações: “Ela está num disco infantil?"}

No corpus coletado, é notável a quantidade de regravações de canções originárias da esfera discursiva para adultos. Os CD's da banda Pato Fu são compostos somente por regravações; os de Adriana Partimpim mesclam autorais e regravações; e os do grupo Pequeno Cidadão possuem, predominantemente, canções autorais. Isso nos faz pensar como essas canções, não pensadas originalmente para esse fim, passam a pertencer ao mundo infantil. 
Primeiramente, é necessário explicitar o consenso do qual partimos para afirmar que essas regravações pertencem ao posicionamento para crianças, logo constroem também a identidade deste. Entendemos que a fixação de um fonograma, explicitamente dedicado ao público-alvo infantil, imputa, desde já, considerar certa intencionalidade do(s) produtor(es). Entretanto, não apenas isso é necessário para que nossa perspectiva considere o pertencimento; não basta o que declaram os sujeitos, é necessário analisar suas práticas discursivas.

Assim, com base no trabalho de Mendes (2017), podemos caracterizar uma prática recorrente nas regravações de canções do posicionamento em questão que explicita a mudança do pertencimento para o contexto infantil: a retextualização. Para o presente trabalho, consideramos processos de retextualização aqueles em que a materialidade enunciativa é modificada no plano da letra, no plano vocal, nos instrumentos, na melodia e/ou no fonograma. Faz-se notar que, um processo de retextualização implica um processo de recontextualização, esse último entendido como a mudança de situação/contexto comunicativo. Dessa forma, encontramos nas canções selecionadas processos retextualizadores que buscam criar efeitos de sentido que, por sua vez, validem novas interpretações e, em especial, sua mudança de público.

Ainda que Mendes (2017) pouco relacione sua análise com os posicionamentos, tendo em vista que seu objetivo é a caracterização dos processos retextualizadores, a autora seleciona e analisa três canções que também compõem nosso corpus, são elas: "Fico assim sem você" (ADRIANA PARTIMPIM, 2004), "Gatinha manhosa" (ADRIANA PARTIMPIM, 2009) e "Primavera" (PATO FU, 2010). Dá-se destaque aos investimentos instrumental e vocal como possibilitadores de uma mudança cenográfica, ou seja, um investimento cenográfico distinto do original. Como em "Primavera", em que a cenografia primeira nos remete diretamente à declaração de amor entre um casal apaixonado e que, todavia, é alterada na regravação de Pato Fu, tendo maiores possibilidades de ser interpretada como declaração entre pais e filhos, entre amigos, etc. 
Gostaríamos de acrescentar a esse tipo de retextualização o exemplo da canção "Love me tender" (PATO FU, 2010), em que, também, não há alterações no plano da letra, mas um investimento cenográfico distinto, relacionado aos instrumentos e a um investimento vocal. Na canção original de Elvis Presley, a cenografia e o investimento vocal do cantor corroboram uma ambientação exageradamente romântica de amor entre um casal; contudo, na regravação, os instrumentos, como xilofone e caixa de música à manivela, ambientam uma cenografia validada de canção de ninar, corroborada pela voz suave da intérprete Fernanda Takai. Destacamos, também, o investimento em um plurilinguismo externo.

Ainda no mesmo fonograma, encontramos a canção "Pelo interfone" (PATO FU, 2010), em que percebemos uma mudança por meio do ethos do enunciador relacionado ao conflito da crise amorosa na infância, como já explicitado. O trecho "O meu coração já não aguenta/ Bate forte, quase arrebenta!" pode ser facilmente interpretado como uma situação de namoro infantil com uma forte dependência e exagero/imprecisão na expressão dos sentimentos; já na primeira gravação, a interpretação mais latente é a do relacionamento amoroso erótico, reforçada no trecho "Ela me olha meio displicente/ O dia vai chegar/ Uma noite a menos para a gente!"; como iremos apontar mais adiante, parece-nos que os novos investimentos discursivos buscam um apagamento da sensualidade, quando esta existe na primeira gravação.

Um caso especial é o da canção “Telefone” (2016), que é a exceção de regravação em meio às autorais, do grupo Pequeno Cidadão. Isso torna a análise da canção mais curiosa, afinal devemos pensar os fatores da eleição desse rock dos anos 1980 para composição do fonograma. Primeiramente, é necessário notar que uma das fundadoras do grupo, Ticiana Barros, foi integrante da banda Gang 90 e as Absurdettes, da qual provém a primeira gravação. Notamos também que a canção há muito vem sendo regravada por outras bandas de rock, como Skank e Ira!. Assim, o grupo Pequeno cidadão, principalmente neste fonograma, assume mais fortemente sua relação com esse gênero musical. Em 
termos acústicos, a regravação deu destaque à figura do telefone por meio da inserção de efeitos de áudio que imitam um aparelho telefônico recebendo ligações; podemos relacionar isso ao caráter lúdico trazido pela sonoridade com o arranjo. Já a cenografia, quando aliada ao investimento vocal do protagonismo de vozes com identidades infantis, revela-se diferente da original no sentido de grau de compromisso entre as relações; na primeira, parece prevalecer a ideia de um amor concreto à distância, enquanto a regravação se associa a um contexto socialmente reconhecido de relações infantis que, por causa das restrições para o encontro físico, mantém contato por telefone para reafirmar o amor, como sugere o refrão "Oh meu amor/ Isso é amor". Além disso, o trecho "Pode ser de São Paulo a Nova York/ Ou tão lindo flutuando em nosso Rio/ Ou tão longe mambeando o mar Caribe/ A nossa onda de amor não há quem corte" cria a imagem de um enunciador globalizado atrelado ao sentimento amoroso; assim, o amor é entendido como um sentimento sem fronteiras.

Já o grupo Pato Fu (2017) regravou duas canções referentes à temática amorosa que possuem traços de polemicidade, quando considerados os contextos das primeiras produções. "I Saw You Saying (That You Say That You Saw)" foi um dos hits do segundo CD da banda Raimundos, "Lavô tá novo" (1995). Desde o título do fonograma até as letras das demais canções, o álbum original é hiper erótico, repleto de duplo sentido e termos sexuais explícitos. Contudo, apesar dessa inospitalidade ao contexto infantil, a canção é a quarta faixa escolhida por Pato Fu para ser regravada em seu segundo CD de "Música de brinquedo". A primeira consideração discursiva refere-se ao processo de recontextualização que retira essa canção da situação comunicativa eroticizada e relaciona-a com as demais do fonograma para crianças.

No que diz respeito aos processos de retextualização na canção "I Saw You Saying (That You Say That You Saw)" (PATO FU, 2017), podemos destacar que, apesar de nenhuma mudança no plano da letra, o investimento cenográfico, aliado ao investimento ético, cria uma nova ambientação para a canção, a da idealização amo- 
rosa de uma criança por um adulto. O enunciador parece estar apaixonado por uma mulher estrangeira e decide perguntar sobre o que ela acha dele; ele, então, recebe uma resposta em inglês e, tendo declarado que "Eu não sei falar inglês/ Ela não entende uma palavra em português", busca o intermédio do pai, que repete a mesma resposta em inglês. O fato de não saber inglês e o de buscar ajuda na figura do pai pode reforçar a interpretação de que o ethos do enunciador é de uma criança. Como o plano da letra não foi alterado, mantém-se o trecho "I feel good because you put your butt on $m e^{\prime \prime}$, que parece inapropriado ou incompreensível para a projeção de criança do senso-comum; contudo, imaginamos que seja, justamente, esse o principal efeito de sentido almejado, assim como o enunciador-criança não compreende a sensualidade explícita (para os adultos), o delocutor-criança também não a compreenderá durante a audição. Convém destacar também que esse trecho, assim como a maior parte da canção, não é cantado por crianças, ou seja, busca-se não relacionar essa possível sensualidade com uma identidade vocal infantil.

Contudo, polêmica maior gerou a regravação de "Severina Xique-Xique" (PATO FU, 2017). Após o lançamento de "Música de brinquedo 2", diversos canais midiáticos noticiaram a ousadia do grupo ao regravar, em um álbum para crianças, uma canção conhecida popularmente pelo duplo sentido; como na notícia, veiculada no site G1, intitulada "Pato Fu traz malícia sexual de hit de Genival Lacerda para álbum infantil" (FERREIRA, 2017). Em entrevista, o compositor João Gonçalves parece se surpreender ao receber a notícia da regravação, mas ressalta sua intencionalidade isenta de duplo sentido ao compor a canção:

Não estava sabendo [...]. Ela está num disco infantil? (ri). Também Severina não tem essas malícias todas, fiz pensando em boutique, porque foi quando surgiu, estava começando esse tipo de negócio. Lá no Sul não sabem que aqui no Nordeste boutique tem o masculino. A música nem chegou a ser censurada (GONÇALVES, 2017).

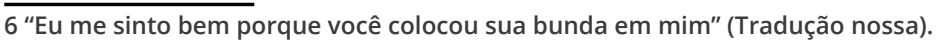


Também em entrevista, quando perguntada sobre a repercussão da regravação na internet, a cantora Fernanda Takai, principal vocalista do grupo, respondeu:

\begin{abstract}
Eu acho que isso faz muito parte da cultura brasileira. Eu cresci nos anos 1960 e ouvi "Severina Xique-Xique" quando criança, e ela não é, de nenhuma forma, uma música agressiva. Acho que hoje as pessoas escutam coisas muito mais explícitas do que isso. [...] Sobre a repercussão nas redes sociais, creio que se a banda aprendeu algo em 25 anos foi a não ter medo de seguir com as nossas ideias (TAKAl, 2017a).
\end{abstract}

Como já mencionamos, para nossa perspectiva, o que declaram os sujeitos-autores deve ser considerado, mas não restringe os efeitos de sentido, como no caso de João Gonçalves que não pretendia que seu texto fosse lido com duplo sentido, porém a canção ganhou popularidade justamente por isso, em razão dos regionalismos linguísticos.

Ao analisarmos as práticas de retextualização na regravação de "Severina Xique-Xique", encontramos, primeiramente, sutis mudanças no plano da letra. Essas não ocorrem nos trechos de voz cantada, mas alteram um diálogo em voz falada, advindo da primeira, que se dava entre a repetição das estrofes e refrão. Para melhor visualização, no quadro abaixo, à esquerda, encontram-se os trechos do fonograma de 1975 e, à direita, os trechos alterados da regravação. 
O amor é pop: canções e posicionamento pop-rock para crianças

Maria das Dores Nogueira Mendes • José Wesley Vieira Matos

\section{Quadro 1. Comparação das letras de "Severina Xique-Xique"}

Severina, minha filha, não vá na onda de Pedro

Olha! Ele só tem interesse em você, sabe por quê?

Porque você tem uma boutique, minha filha!

Agora você querendo um sócio, olha aqui seu Babá (risada)

\section{$[\ldots]$}

Oh Severina, como é? Resolve, minha filha!

Se tu quiser, passa-lá! Ha-hai...

Ai meu Deus! Mas Severina tá bonita mesmo. Oh bem, vai lá.
Severina, minha filha, não vá na onda de Pedro. Ele só está interessado em você, sabe por quê? Só porque você tem uma boutique, minha filha! Esse Pedro Caroço aí é um bobão. Larga ele pra lá.

$[\ldots]$

(risada) Ô Severina, como é? Resolve, minha filha. Agora você querendo um sócio... Olha aqui seu monstrinho (risada) Passa lá, minha filha. Agora esse Pedro Caroço é um monstro. Opa! Eu também sou. Tchau, filha!

O ethos projetado de Severina corresponderia ao da canção original, no seu sentido mais literal, uma moça pobre que se tornou dona de um pequeno estabelecimento comercial, boutique; da mesma forma, o ethos projetado de Pedro Caroço permanece o de um rapaz interesseiro, financeiramente, que pretende enganar Severina com falsos sentimentos. Contudo, a cenografia, aliada ao investimento vocal, dá um novo enfoque ao conflito relacionado ao sentimento amoroso. Na primeira gravação, a primeira e a segunda estrofe do diálogo são faladas pelo intérprete com a mesma identidade vocal, o que nos conduz a duas possíveis interpretações: na primeira, podemos relacionar o diálogo a um ethos ríspido e insensível do pai de Severina, marcado pelo uso do vocativo "minha filha", no sentido de laço familiar; já na segunda interpretação, relacionamos o diálogo ao autoproclamado "Seu Babá", o interesseiro pretendente que denuncia Pedro Caroço, mas incorre no mesmo erro, e o vocativo "minha filha" estaria mais ligado ao sentido de afetividade, ainda que maliciosa. 
Já na regravação, encontramos duas identidades vocais distintas, revelando que, não só no plano da letra, mas principalmente no plano vocal, o grupo Pato Fu separa os dois possíveis enunciadores e funde as interpretações anteriores. A primeira estrofe é falada por uma criança (voz feminina e em tom imperativo) e alerta Severina da motivação interesseira de Pedro Caroço; o trecho que menciona "seu Babá" é transferido para a outra estrofe e acrescenta-se o termo "bobão" à primeira, ofensa infantilizada, referindo-se a Pedro. Enquanto esse primeiro trecho parece empoderar Severina, aconselhando-a a se livrar de relações por interesse, o que poderíamos relacionar à figura materna (já que a voz passou a ser feminina), o seguinte possui sentido contrário, tendo proximidade com o pretendente "Seu Babá". Nele, a identidade vocal é de um monstro, o boneco Groco do teatro Giramundo, manipulado por Ulisses Tavares, e esse investimento vocal reforça o conteúdo do plano da letra em que o enunciador do diálogo faz uma proposta por interesse à Severina, ignorando seus sentimentos, acusando Pedro de ser um monstro e, consciente do teor maléfico de sua fala, admitindo ser também um monstro. Assim, o polissêmico termo "monstro" refere-se tanto a uma atribuição ruim, pelas atitudes interesseiras, como trata-se de uma intervocoverbalidade", em que a "voz de monstro" recai sobre os termos "monstrinho" e "monstro", reforçada também pelas risadas "maléficas".

Dessa forma, percebe-se que a regravação complexifica as relações de ordem materialista e sentimental entre os personagens, dando foco ao jogo de interesses, causando, assim, um apagamento do duplo sentido que poderia haver no refrão. Convém notar também o destaque que ganha, na regravação, o instrumento inusitado associado ao universo infantil, um frango de borracha, trazendo aspectos lúdico e cômico. Além disso, o processo de recontextualização também contribui para que a situação comunicativa ambígua da primeira versão seja ocultada em detrimento de um sentido literal e mais amplo dos termos, lembrando a preferência do posicionamento pela universalidade e não pelos regio-

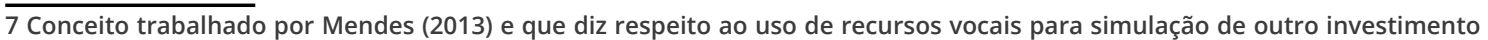
vocal no plano cenográfico de uma canção. 
nalismos, além de ser uma ação linguística esperada por um delocutor criança que não conhece ainda a ambiguidade linguística, principalmente com conotação sexual.

Outro processo de retextualização que gostaríamos de mencionar refere-se à capa do single "Severina Xique-Xique" (2017), divulgada no canal do Grupo Pato Fu na plataforma YouTube. A ilustração é de Anna Cunha e há uma clara relação intertextual (imagética) com a capa do fonograma original de Genival Lacerda; nela, o boneco que representa o integrante da banda, Glauco Mendes, possui vestimentas similares às de Genival, além da semelhança na disposição dos elementos linguísticos de identificação do fonograma. Cremos que essa relação revela o cuidado do grupo (e em generalização, do posicionamento) no que diz respeito à transposição da canção para a esfera infantil; muitos elementos originais são retomados em todo texto/canção, mas com outro tratamento.

Figura 2. Ilustração do single "Severina Xique-Xique"

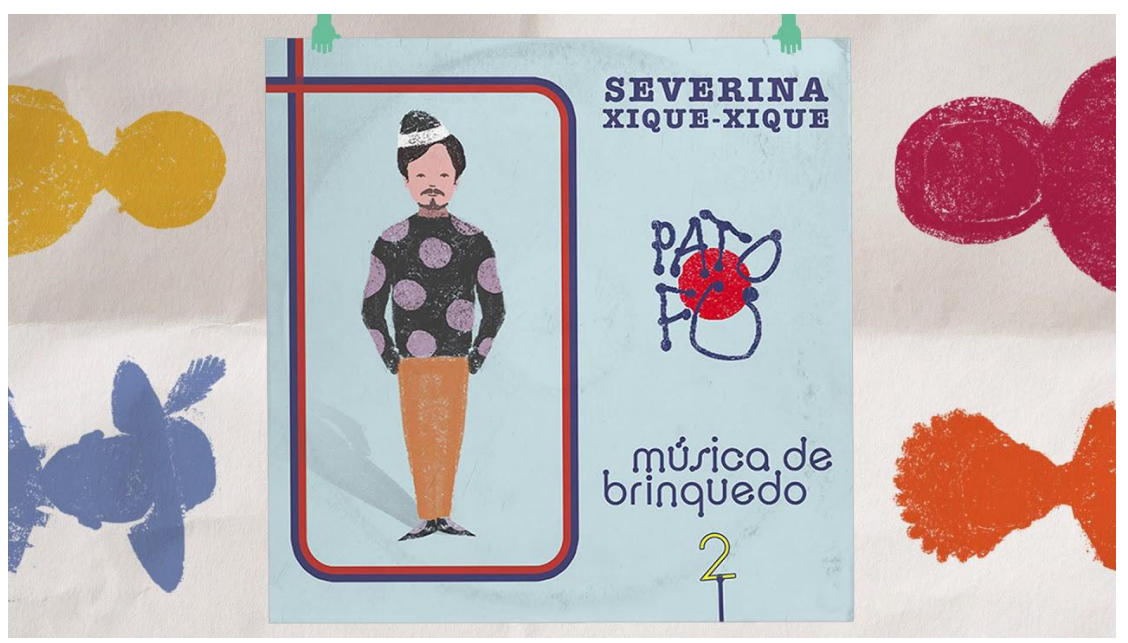

Fonte: Canal Oficial do grupo Pato Fu na plataforma YouTube (2017)8.

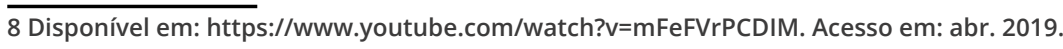




\section{Progressistas e românticos: “O vento diz 'ele é feliz"'}

Percebemos que as relações afetivas no posicionamento pop-rock para crianças são complexas, no sentido de apresentar não somente a felicidade proveniente dos relacionamentos, mas os conflitos possíveis também, causando uma primeira impressão de insensibilidade, frieza. Contudo, apesar de termos dado destaque a esse aspecto diferenciador do posicionamento, não é ele único e dominante no que diz respeito à temática amorosa.

Primeiramente, é necessário destacar aquilo que, talvez, já se encontra perceptível anteriormente: há uma flutuação entre o amor de amigo (philia) e o amor de casal (eros). Tanto em termos de transição como no caso da canção, já mencionada, "Mesmo sem a gente" (PEQUENO CIDADÃO, 2016), em que o enunciador pede que seu/sua ex-companheiro/a amoroso/a perdoe um possível erro e se tornem amigos, como também em termos de oscilação, caso da canção "Oi, hello" (PEQUENO CIDADÃO, 2012), em que o enunciador não especifica o tipo de relação que pretende manter: "Eu tenho um sorriso/ nos meus lábios pra te dar/ E olhos nos olhos/ nós podemos conversar/ Me lembro quando conquistei/ $O$ meu primeiro amor". Também convém destacar o recorrente ethos aprazível nas constantes saudações, e de conciliação, como explicitado no trecho "Queria mesmo bem no fundo/ do meu coração/ que as brigas fossem resolvidas/ com aperto de mão". Além disso, observamos que a canção possui um investimento plurilinguístico, aliado ao investimento vocal em identidades infantis, bem diversificado ao mencionar diversas saudações, como em "Eu digo oi até em japonês/ que é konichiwa" e "Eu digo oi até em francês/ Comment allez-vous".

Além dessa presença constante do clima de amizade, também há canções voltadas para o sentimento amoroso erótico (de eros), mais especificamente para a sensação de estar apaixonado. Como na regravação de "Lindo lago do amor" (ADRIANA PARTIMPIM, 2012), em que os elementos da natureza, primeiramente cantados 
O amor é pop: canções e posicionamento pop-rock para crianças

Maria das Dores Nogueira Mendes • José Wesley Vieira Matos

por Gonzaguinha (1984), perdem a metaforização e ganham mais traços de animalidade (no duplo sentido de ser animado e ser um animal) $^{9}$ ao projetarem um ethos de um sujeito apaixonado e, por isso, contente: "O vento diz 'ele é feliz"'.

Já em "Ringtone do amor" (ADRIANA PARTIMPIM, 2009), podemos recuperar um contexto antigo, datado dos anos 1990, mas que atingiu seu auge na primeira década dos anos 2000, a difusão do toque de celular. Como explicitado na notícia de Costa (2017), os ringtones fizeram muito sucesso a partir da possibilidade de utilizar toques polifônicos, sucedidos pelos hits da época e, posteriormente, pela personalização de toques, como a inserção do nome próprio ou do nome do/a companheiro/a em uma melodia. Assim, a cenografia se constrói rememorando os repetitivos toques, com breves letras e que, comumente, se referiam a uma metadiscursividade ${ }^{10}$; características transportadas para a canção autoral de Partimpim, como nos versos “Um ringtone pra chamar você/ Um ringtone pra dizer seu nome/ Um ringtone para ouvir você dizer: alô". Assim, alia-se a esse contexto de declaração amorosa um ethos enamorado que, mesmo na ausência física, deseja estar presente e ser lembrado.

Fazemos notar também as canções, já mencionadas em todo o trabalho, que abordam o amor de uma perspectiva positiva de felicidade, como "Telefone" (PEQUENO CIDADÃO, 2016) e "Fico assim sem você" (2004); além de outras interpretações que não estão em nosso corpus, mas revelam esse caráter romântico do posicionamento pop-rock para crianças, como "O mocho e a gatinha" do DVD "Adriana Partimpim: o show". Isso nos leva a perceber como o posicionamento, ao abordar a temática amorosa, não apresenta o sentimento sob uma ótica maniqueísta, pois, ao passo que se canta as possibilidades da crise amorosa, canta-se também a romantização atrelada à felicidade; assim, os investimentos apontam uma compreensão da integração desses aspectos e não um antagonismo das ideias.

\footnotetext{
9 Ideia reforçada pelos elementos imagéticos, fantoches de animais e um boneco em um lago, presentes no videoclipe da canção. Disponível em: https://www.youtube.com/watch?v=Mp6uXexDyaQ. Acesso em: abr. 2019.

10 Como se pode averiguar em propagandas da época: https://www.youtube.com/watch?v=WkQyfGOxFhs. Acesso em: abr. 2019.
} 


\section{Amor pop-rock: "Gerador do motor de revolucionar"}

Como havíamos mencionado, o posicionamento em questão foi delimitado pelo projeto de pesquisa INVOCANÇÕES em sua primeira fase, e o principal objetivo deste estudo foi traçar aspectos gerais sobre aquele, tendo como pretexto a análise de canções com a temática amorosa. Assim, em continuidade, visamos a estabelecer relações entre a esfera discursiva do pop-rock para adultos e a esfera para crianças, buscando semelhanças e distinções; considerando, também, a conexão constitutiva entre os sujeitos adultos (no caso, oriundos de outra prática literomusical) produtores das canções e o público almejado que dá sentido às especificidades de uma nova prática.

Seguindo as conceituações de Costa (2012), o Pop [para adultos] localiza-se em um agrupamento de posicionamentos em torno de valores relativos à tradição. Como também assinala Peixoto (2005), podemos perceber os movimentos contrários do posicionamento MPB e Pop, enquanto a MPB converge para o centro da tradição, o Pop busca distanciar-se dela; tradição esta entendida como "[...] o conjunto de valores que se propõe caracterizar, representar a identidade brasileira" (PEIXOTO, 2005).

Podemos notar que, em termos de nacionalismo, as canções do Pop-rock para crianças analisadas não pretendem ser topograficamente limitadas, mas transparecem um desejo pela globalização. Contudo, em reflexões do Grupo Discuta, percebemos que o dito cosmopolitismo do Pop para adultos é fortemente marcado por um eurocentrismo (e/ou anglocentrismo, considerando a inclusão dos Estados Unidos); enquanto no Pop para crianças há uma diversidade maior de nações sendo memoradas. Essa ampliação de horizontes reflete-se também no fenômeno do plurilinguismo externo, que, no Pop-rock para crianças, passa a abranger mais línguas, como o japonês; enquanto a MPB privilegia e ressalta a língua portuguesa, como na canção "Gramática" do grupo Palavra Cantada. Devemo-nos atentar, ainda, às influências contextuais 
dos produtores, como, por exemplo, a ascendência portuguesa e japonesa da cantora Fernanda Takai, que marca uma maior "orientalidade" nas produções de Pato Fu.

Motivados pela análise, gostaríamos de ampliar essa oposição dos posicionamentos, no que tange à noção de tradição, dentro da esfera para crianças. Inspirados no trabalho de Pinho (2007), acreditamos que seja importante considerar a projeção dos sujeitos nas canções. Assim, em nosso contexto de análise, entendemos também "tradição" como o conjunto mais estabilizado de valores relativos à infância, em outros termos, a concepção de criança mais difundida. Segundo Pinho (2007), o sujeito das canções do Pop para adultos, em especial nas canções de Adriana Calcanhotto, encontra-se em crise sobre a própria identidade e isso está relacionado às condições da pós-modernidade.

As canções do Pop-rock analisadas certamente não apresentam uma concepção de criança em crise, tal como o sujeito do Pop para adultos; ao passo que esse sujeito-adulto possui um ethos consciente e questionador das concepções de si mesmo, o sujeito-criança possui, primeiramente, um ethos de curiosidade, como consta na identificação do grupo Pequeno Cidadão (2019): “[...] para crianças bagunceiras e muito sabidas". Assim, confiados nessa autonomia pensante da criança, o posicionamento entende seu sujeito-delocutor como um indivíduo em construção em muitos aspectos da vida e caracteriza-o como uma potencial esperança para mudanças.

Essa concepção contraria o que poderíamos chamar de tradição no segundo sentido que expomos. O posicionamento MPB para crianças compreende seu sujeito aos moldes de uma concepção moderna de criança; segundo Ariès (1981), durante a modernidade, observa-se uma mudança na forma de compreender o núcleo familiar não somente como provedor, mas como núcleo afetivo; surge, então, o "sentimento de infância" atrelado ao senso de responsabilidade e afetividade dos pais. Essa concepção moderna sobre a criança projeta nesse sujeito aspectos de fragilidade e inocência, logo, um sujeito com pouca autonomia que requer 
O amor é pop: canções e posicionamento pop-rock para crianças

Maria das Dores Nogueira Mendes • José Wesley Vieira Matos

preservação. A forte influência do romantismo consolida não só no senso comum essa concepção de criança, mas a transpõe ao discurso religioso, literário, etc. Assim, podemos alçar essa concepção ao status de tradição a respeito do que se projeta sobre a infância.

Por exigências de delimitação, podemos, então, pensar que a MPB para crianças se alinha a essa concepção moderna/tradicional, enquanto o Pop-rock para crianças busca se distanciar dessa tradição recorrendo a um sujeito imerso em um contexto pós-moderno. Não gostaríamos de traduzir essa diferença em termos de uma concepção pós-moderna ${ }^{11}$ sobre a criança, ainda que alguns trabalhos, como o de Zadorosny (2006), já discutam as novas relações da contemporaneidade com esses sujeitos ${ }^{12}$; mas, na falta de termo melhor, pretendemos assim evidenciar essa concepção oposta à tradição/modernidade e que pretende superá-la, ou seja, uma concepção após a modernidade.

Dessa forma, essa contrariedade dos posicionamentos presente na esfera adulta é também reconhecível na esfera infantil, e isso não se dá somente nas canções, mas torna-se explícito na forma dos integrantes comunicarem-se e ao expressarem suas opiniões. Podemos identificar uma polêmica implícita na fala já citada de Takai (2017a), ao admitir não ter medo de uma possível censura das produções do grupo; enquanto na MPB para crianças observamos as seguintes declarações dos intérpretes do grupo Palavra Cantada em entrevista à revista Comunicação e Educação (2006):

C \& E: Então poderíamos dizer que qualquer tema serve para música infantil?

Paulo Tatit: Qualquer tema, não. Os temas de amor ficam de fora, porque as crianças não têm idade ainda. É um grande tema para música adulta, mas para elas é melhor outro. [...]

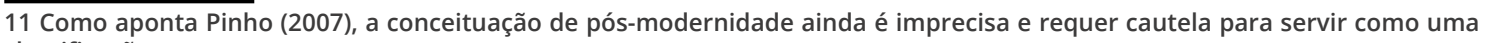
classificação.

12 Interessante que, nesse estudo, faz-se notar as influências das novas tecnologias (celulares, videogames) na vida das crianças, considerando esses elementos como inserções pós-modernas que modificam os sujeitos. Podemos relacionar essa dimensão contextual à recorrente menção que ocorre, nas canções do posicionamento Pop-rock, ao aparelho telefônico, e que, diferentemente daquilo que defende o estudo, não possui um valor negativo, sendo tratado como posto na nova realidade.
} 
Paulo Tatit: É, o amor, a dor de cotovelo, a desilusão amorosa, isso é para uma outra faixa etária. [...]

Sandra Peres: Quem canta é a Adriana Calcanhotto. É aquela: 'Amor sem beijinho, Buchecha sem Claudinho, sou eu assim sem você'. Essa é a música das paradas. É bonita e também foi colocada numa novela. Tem uma exposição que gera esse sucesso. Mas discordo que essa música que faz tanto sucesso seja uma música infantil.

Assim, podemos reconhecer que a MPB para crianças, considerando o Palavra Cantada como um importante representante, busca restringir certos temas ao público infantil, mencionando como exemplo justamente a temática central desta pesquisa, o amor. A polêmica se dá em diversos níveis, desde as concepções opostas nas letras das canções até a remição de Paulo Tatit à "desilusão amorosa", que, como defendemos anteriormente, constitui um aspecto central para o posicionamento Pop-rock para crianças sob os termos de "crise amorosa"; chegando ainda à citação direta de um trecho da canção "Fico assim sem você" (ADRIANA PARTIMPIM, 2004), constituinte do posicionamento oposto, para explicitar a discordância da inserção desta ao contexto infantil. Essa polêmica reforça a noção do agrupamento para adultos e pode ser verificada na esfera infantil, enquanto a MPB afirma-se como a "verdadeira música" e de "melhor qualidade", o Pop busca distanciar-se dos espaços-comuns de aceitação em constante ethos de rebeldia.

Outro aspecto que ressalta essa oposição constitutiva dos posicionamentos para crianças é o investimento vocal. Ao passo que a MPB para crianças dedica especial atenção às qualidades vocais (MATOS, 2020), se alinhando a um paradigma de "perfeição", o Pop-rock para crianças investe em uma "naturalização" das vozes infantis, contrariando e afastando-se dessa tradição de "beleza" vocal. Isso é também explicitado pela vocalista do grupo Pato Fu ao afirmar que as crianças "são meio desafinadas, não é tudo limpinho. Neste caso, a imperfeição é boa, o erro é legal, pois é uma criança que está ali" (TAKAl, 2017b). 
Esse referido ethos, comum aos posicionamentos Pop's nas duas esferas, também os aproxima em outras características, como a aversão a rotulações. Conforme Peixoto (2005), os artistas do Pop para adultos, de maneira geral, buscam distanciar-se de qualquer categorização. Pudemos perceber atitudes similares nas declarações recortadas no início deste trabalho, em que alguns integrantes do Pop para crianças negam sua dedicação exclusiva para crianças, justificando as canções como "não-gênero" ou afirmando que "não é (ou não somente) para crianças". Assim como Peixoto (2005), relacionamos essa deslocalização com o conceito de paratopia (MAINGUENEAU, 2001b), uma tentativa de fugir dos rótulos para reforçar uma identidade "independente".

Retomando o que já foi apresentado sobre as canções com cunho amoroso no posicionamento analisado, gostaríamos de ressaltar o alinhamento que há entre as canções e os integrantes na construção de uma identidade libertária que compreende o amor como escolha; tanto a escolha de quem ama quanto a de quem corresponde (ou não) a esse amor. E isso nos remete ao apontamento mais amplo que há sobre as temáticas do Pop segundo Costa (2012): “A grande temática da canção pop é a liberdade, em todos os aspectos: sexual, político, comportamental etc.".

Contudo, conforme observamos, essa liberdade ou "falta de censura" não acarreta a equiparação do sujeito-criança a um adulto; basta lembrarmo-nos que, no corpus analisado, a sensualidade das canções para adultos sofreu apagamento através de processos retextualizadores. Além da diferença, já mencionada, entre compreender o sujeito como pleno de consciência e capaz de mudanças (Pop para adultos) e compreender a criança como sujeito em formação.

Dessa forma, torna-se notável que o amor, no Pop-rock para crianças, não constitui apenas uma temática recorrente, mas se integra como uma bandeira que compõe a identidade libertária do posicionamento; é tanto que, ao observar, por exemplo, a descrição de temáticas do grupo Pequeno Cidadão (2019), encontramos explicitado: “Nossas canções, animações e livros retratam o uni- 
verso infantil: alegrias, dúvidas, bichos, desafios, tristezas, cidadania, esportes, amor" (grifo nosso). Além do destaque que ganha em canções como "Menina, menino", autoral de Adriana Partimpim (2009), em que o enunciador fia, explicitamente, a ideia da suma importância do amor como agente transformador; utilizando o vocativo "menina, menino" para convocar as crianças, caracterizando o amor como "gerador do motor de revolucionar" e, também, advertindo: "Não deixe de amar/ o amor é o que há".

\section{Referências bibliográficas:}

ARIÈS, P. História social da criança e da família. Rio de Janeiro:

Editora Guanabara, 1981.

CALCANHOTTO, A. Adriana Calcanhotto. "Não me sinto apegada à carreira musical". Revista Isto É, 2004. Disponível em: https://www.terra. com.br/istoegente/269/entrevista/index.htm. Acesso em: 20 abr. 2019.

COSTA, D. Quem se lembra dos ringtones? Portogente, 2017.

Disponível em: https://portogente.com.br/noticias/opiniao/

97467-quem-se-lembra-dos-ringtones. Acesso em: 20 abr. 2019.

COSTA, N. B. Música popular, linguagem e sociedade: analisando o discurso literomusical

brasileiro. Curitiba: Editora Appris, 2012.

COSTA, N. B. A Produção do Discurso Literomusical Brasileiro para

Crianças: uma proposta de investigação discursiva. Projeto de pesquisa apresentado ao Departamento de Letras Vernáculas da Universidade Federal do Ceará, 2013. Disponível em: http://www.repositorio.ufc.br/ handle/riufc/19881. Acesso em: 20 abr. 2019.

FERREIRA, M. Pato Fu traz malícia sexual de hit de Genival Lacerda para álbum infantil. G1, 2017. Disponível em: http://g1.globo.com/musica/blog/mauro-ferreira/post/pato-fu-traz-malicia-sexual-de-hit-de-genival-lacerda-para-album-infantil.html. Acesso em: 20 abr. 2019.

GONÇALVES, J. João Gonçalves, o censurado autor de Severina XiqueXique. JC online, 2017. Disponível em: https://jconline.ne10.uol.com.br/ 
canal/cultura/musica/noticia/2017/08/30/joao-goncalves-o-censurado-autor-de-severina-xique-xique--304208.php. Acesso em: 20 abr. 2019. GONZALEZ, B. N. A. C. Posicionamentos discursivos na música popular brasileira para crianças. Dissertação (Mestrado em Linguística), Centro de Humanidades, Universidade Federal do Ceará, Fortaleza, 2014. Disponível em: http://www.repositorio.ufc.br/handle/riufc/8906. Acesso em: 20 abr. 2019.

MAINGUENEAU, D. Análise de textos de comunicação. Tradução Souza-e-Silva, C. P.; ROCHA, D. São Paulo: Cortez, 2001 a.

MAINGUENEAU, D. Cenas da enunciação. Organizado por Sírio Possenti e Maria Cecília Pérez de Souza-e-Silva, diversos tradutores. Curitiba: Criar Edições, 2006.

MAINGUENEAU, D. Discurso e análise do discurso. Tradução de Sírio Possenti. São Paulo: Parábola, 2015.

MAINGUENEAU, D. Gênese dos discursos. Tradução de Sírio Possenti. Curitiba: PR, 2005.

MAINGUENEAU, D. O contexto da obra literária. Tradução de Marina Appenzeller. São Paulo: Martins Fontes, 2001b.

MATOS, J. W. V. Relacionamento amoroso em canções para crianças. In: V Colóquio Internacional de Análise do Discurso, 2020, São Carlos.

\section{Anais do V CIAD Colóquio Internacional de Análise do Discurso}

- Discurso e (pós) verdade: efeitos do real e sentidos da convicção. Araraquara: Letraria, 2020. v. 1. p. 731-741. Disponível em: http://www. ciad.ufscar.br/?page_id=1099. Acesso em: 13 ago. 2020.

\section{MENDES, A. F. F. O processo de retextualização na canção para} crianças: uma abordagem discursiva. 2017. 166f. Tese (Doutorado) - Universidade Federal do Ceará, Programa de Pós-graduação em Lingüística, Fortaleza, 2017. Disponível em: http://www.repositorio.ufc. br/handle/riufc/26748. Acesso em: 20 abr. 2019.

MENDES, M. N. M. O duro aço da voz: investimento vocal, cenografia e ethos em canções do Pessoal do Ceará. 2013. 339f. Tese (Doutorado) - Universidade Federal do Ceará, Departamento de Letras Vernáculas, Programa de Pós-graduação em Linguística, Fortaleza, 2013. Disponível 
em: http://www.repositorio.ufc.br/handle/riufc/8236. Acesso em: 20 abr. 2019.

PARTIMPIM, A. Site oficial: Entrevista. s/d. Disponível em: http://www. adrianapartimpim.com.br/um/entrevista.htm. Acesso em: 20 abr. 2019. PEIXOTO, M. V. O tropicalismo e a cultura pop - um encontro interdiscursivo em Adriana Calcanhotto. 2005. 128 f. Dissertação (Mestrado) - Universidade Federal do Ceará, Departamento de Letras Vernáculas, Programa de Pós-Graduação em Linguística, Fortaleza, 2005. Disponível em: http://www.repositorio.ufc.br/handle/riufc/5834. Acesso em: 20 abr. 2019.

PEQUENO CIDADÃO (Januária Alves). A fantástica viagem do pequeno cidadão. São Paulo: LeYa, 2010.

PEQUENO CIDADÃO. Site oficial, c. 2019. Disponível em: https://www. pequenocidadao.com/. Acesso em: 20 abr. 2019.

\section{PERES, S.; TATIT, P. A música para crianças da dupla Palavra}

Cantada. São Paulo: Revista Comunicação \& Educação. Entrevista concedida a Roseli Fígaro, p. 69-82, 2006.

PINHO, F. S. N. “O pop não poupa ninguém": relações discursivas entre o pop rock e a pós-modernidade. 2007.134 f. Dissertação (Mestrado) - Universidade Federal do Ceará, Departamento de Letras Vernáculas, Programa de Pós-Graduação em Linguística, Fortaleza-CE, 2007.

Disponível em: http://www.repositorio.ufc.br/handle/riufc/6114. Acesso em: 20 abr. 2019.

TAKAI, F. Pato Fu: "Não é um disco infantil”, diz Fernanda Takai sobre Música de Brinquedo 2, que tem letra polêmica com "duplo sentido". Oul-Rolling Stone, 2017a. Disponível em: https://rollingstone.uol.com. br/noticia/pato-fu-musica-brinquedo-2-nao-e-um-disco-infantil-fernanda-takai/. Acesso em: 20 abr. 2019.

TAKAI, F.. Pato Fu volta a apostar em músicas infantis no novo disco. Diário de Pernambuco, 2017b. Disponível em: https://www.diariodepernambuco.com.br/noticia/viver/2017/09/pato-fu-volta-a-apostar-em-musicas-infantis-no-novo-disco.html. Acesso em: 20 abr. 2019. 
TAKAl, F.. Pato Fu: música de brinquedo e de brincar. Revista Crescer, 2011. Disponível em: http://revistacrescer.globo.com/Revista/ Crescer/0,EMI162103-10538,00-PATO+FU+MUSICA+DE+BRINQUEDO+E +DE+BRINCAR.html. Acesso em: 20 abr. 2019.

\section{ZADOROSNY, K. J. A. S. A infância da pós-modernidade e o projeto} moderno inconcluso. 2006. 329 f. Tese (doutorado) - Universidade Estadual Paulista, Faculdade de Ciências e Letras de Araraquara, 2006. Disponível em: http://hdl.handle.net/11449/102334. Acesso em: 20 abr. 2019.

\section{Referências discográficas:}

ADRIANA PARTIMPIM. Fico assim sem você. BMG/Ariola, 2004. ADRIANA PARTIMPIM. Gatinha manhosa. Sony BMG / Sony Music Entertainment, 2009.

ADRIANA PARTIMPIM. Lindo lago do amor. Polysom, 2012. ADRIANA PARTIMPIM. Menina, menino. Sony BMG / Sony Music Entertainment, 2009.

ADRIANA PARTIMPIM. Ringtone do amor. Sony BMG / Sony Music Entertainment, 2009.

PATO FU. I Saw You Saying (That You Say That You Saw). Rotomusic / Deck Disc, 2017.

PATO FU. Love me Tender. Independente, 2010.

PATO FU. Não se vá. Rotomusic / Deck Disc, 2017.

PATO FU. Pelo interfone. Independente, 2010.

PATO FU. Primavera. Independente, 2010.

PATO FU. Severina Xique-Xique. Rotomusic / Deck Disc, 2017.

PEQUENO CIDADÃO. Mesmo sem a gente. MCD, 2016.

PEQUENO CIDADÃO. O Sol e a Lua. MCD, 2009.

PEQUENO CIDADÃO. Oi, hello. Radar Music, 2012.

PEQUENO CIDADÃO. Telefone. MCD, 2016. 